\title{
Tumor Board Saves Lives - More Evidence is Emerging for the Mandatory Development of Site Specific Multi-Disciplinary Teams
}

\author{
Ahmed Nadeem Abbasi* \\ Department of Oncology, Aga Khan University, Karachi, Pakistan.
}

Site specific Multi-disciplinary Tumor Boards play a pivotal role in the provision of high quality comprehensive cancer care. This dictum was thoroughly validated via a number of studies conducted across the world. In our region, our team of cancer carers came forward and we have tried to establish site specific Multi-disciplinary Teams in various institutes of the country and region. As expected, many hurdles of varied nature were encountered by our team and we are still traveller of this journey which we have started on voluntary basis. Site specific teams conduct this activity and maintain quality of these boards [1].

Our multi-disciplinary Tumor Boards are constantly evolving. Starting off with general tumor boards to the development of site specific tumor boards to the use of videoconferencing [2], the MDT tumor board process is continuously been refined to improve the contribution it provides to the cancer care process.

A positive change in clinical practice is being observed and documented across the globe. Though now well established in many parts of the world for decades, in Pakistan we are in the phase of establishment of this activity and published data is scarce [3]. Without much to go by it may be safe to say that generally, the incorporation of these meetings at hospitals providing cancer care is still a work in progress. The fresh blood entering the health care system from medical colleges provides an opportunity to improve this current state.

The scientific evidence shows that MDT tumor boards have been shown to alter management decisions [4] and reduce costs [5]. The success of MDT tumor boards depends on the active and efficient participation of clinicians and effective management by hospital administration to make them productive, taking into account the time and effort that is needed to be put in [6]. A study from the United Kingdom identified participation of key members, provision of description of patient related factors, use of proforma or checklist and patient selection for discussion as important considerations for a successful MDT tumor board [7]. Another study in Canada presented more administrative support, introduction of billing and videoconferencing as suggestions to improve meetings [8]. Studies have also shown that identifying areas of weakness and subsequent measures of intervention can

\footnotetext{
*Address correspondence to this author at the Department of Oncology,
} Aga Khan University, Karachi, Pakistan. E-mail: nadeem.abbasi@aku.edu have a positive impact. The University of Colorado Hospital using the multidisciplinary model has been able to successfully establish multiple site specific clinics where patients have all their required tests, cases discussed and meet the specialists involved all within a period of one to two days [9].

Centers around the world continue to improve the multidisciplinary process to gain more benefit from it and improve the standard of care for their cancer patients we continue to lag behind. We hope to see MDT tumor boards established in all institutes of Pakistan where cancer care is being provided [10].

Practice change requires thorough critical appraisal of contemporary scientific evidence. We are living in the era of rapid technological advancement. Nowadays, offering best management to our cancer patients is still a complex challenge where all avenues of potential benefit must be fully assessed. Multi-disciplinary Tumour (MDT) tumour board tumor boards provide one such avenue. They have been shown not only to alter disease managment1, but also improve patient survival [11]. Not only being of benefit to the patient, it also provides experience to specialists on how to combine treatments along with being a valuable teaching tool for medical students and junior doctors' alike [12].

Across the world MDT tumour board meetings have been shown to yield clinically beneficial outcomes. A study conducted in the UK showed 3 year survival jump from $58 \%$ to $66 \%$ in patients with Duke C stage colorectal cancer by introduction of the MDT [13] tumor board while a study in Australia showed a mean improvement in survival in patients with inoperable non-small cell lung cancer from 205 days to 280 days, when compared with cases discussed in an MDT tumour board meeting with those that were not [14]. Thus showing benefit regardless of place or specialty. These meetings are gradually being conducted by centers treating cancer patients in Pakistan and statistics released by the 'City Tumour Board (CTB) Karachi' showed 264 cases being presented between March 2010 and March 2012 with the initial treatment management plan being changed in $70 \%$ of cases [15]. Along with improving decision making and outcomes, they have shown to drastically decrease the cost of treatment. Establishment of the University of Michigan Multi-disciplinary Melanoma Clinic (UM-MDMC) saved third party payers roughly $\$ 1600$ per patient by improving the 
way resources were used [16]. The reduced cost is of exceptional importance in places such as Pakistan where it is a major limiting factor in the delivery of effective treatment options.

Developing countries will not be able to develop same high standards of comprehensive cancer care if they would fail to establish site specific multi-disciplinary teams in their countries. While, advising our colleagues on the establishment of these multi-disciplinary boards we recommended the frequency of weekly boards with a full back up of a committee overseeing its quality standards and a mechanism of robust monitoring. Introduction of quality indicators and full auditing is obviously not possible in non-mandatory processes, therefore, it is now high time, to develop these site specific boards as a compulsory activity embedded as an essential component of every cancer carers job role and job description.

Comprehensive cancer care and management requires a well-planned strategy. At planning stage all areas of potential benefit are being explored by health care providers. Establishment of site specific Multi-Disciplinary Team (MDT) tumor boards is an important integral component of patient centered plan [17] of service development worldwide [18] across all disciplines which are involved in oncological treatment [19, 20].

The dictum postulating that Tumor Board saves lives of cancer patients is a validated narrative and we hope that site specific multi-disciplinary tumor boards will be established in all healthcare facilities which are providing care to cancer patients.

\section{CONFLICT OF INTEREST}

Declared none.

\section{ACKNOWLEDGEMENTS}

Declared none.

\section{REFERENCES}

[1] Boniface MM, Wani SB, Schefter TE, et al. Multidisciplinary management for esophageal and gastric cancer. Cancer Manag Res 2016; 8: 39. DOI: 10.2147/CMAR.S101169

[2] Dickson-Witmer D, Petrelli NJ, Witmer DR, et al. A statewide community cancer center videoconferencing program. Ann Surg Oncol 2008; 15: 3058-64.

DOI: $10.1245 / \mathrm{s} 10434-008-0101-1$

[3] Lamb BW, Brown KF, Nagpal K, Vincent C, Green JS, Sevdalis N. Quality of care management decisions by multidisciplinary cancer teams: A systematic review. Ann Surg Oncol 2011; 18(8): 2116-25. DOI: 10.1245/s10434-011-1675-6

[4] Wheless SA, McKinney KA, Zanation AM. A prospective study of the clinical impact of a multidisciplinary head and neck tumor board. Otolaryngol Head Neck Surg 2010; 143(5): 650-4. DOI: 10.1016/j.otohns.2010.07.020

[5] Hong NJ, Gagliardi AR, Bronskill SE, Paszat LF, Wright FC. Multidisciplinary cancer conferences: Exploring obstacles and facilitators to their implementation. J Oncol Pract 2010; 6(2): 61-8. DOI: 10.1200/JOP.091085

[6] Jalil R, Ahmed M, Green JS, Sevdalis N. Factors that can make an impact on decision-making and decision implementation in cancer multidisciplinary teams: An interview study of the provider perspective. Int J Surg 2013; 11(5): 389-94.

DOI: $10.1016 /$ j.ijsu.2013.02.026

[7] Wright FC, Lookhong N, Urbach D, Davis D, McLeod RS, Gagliardi AR. Multidisciplinary cancer conferences: Identifying opportunities to promote implementation. Ann Surg Oncol 2009; 16(10): 2731-7. DOI: 10.1245/s10434-009-0639-6

[8] Brar SS, Provvidenza C, Hunter A, et al. Improving multidisciplinary cancer conferences: A population-based intervention. Ann Surg Oncol 2014; 21(1): 16-21.

DOI: $10.1245 / \mathrm{s} 10434-013-3296-8$

[9] Abbasi AN. Cancer management is a multidisciplinary team work. J Coll Physicians Surg Pak 2011; 21(5): 259-61.

[10] Kurpad R, Kim W, Rathmell WK, et al. A multidisciplinary approach to the management of urologic malignancies: Does it influence diagnostic and treatment decisions? In: Droller MJ, Ed. Urologic Oncology: Seminars and Original Investigations. USA: Elsevier 2011; vol. 29, no. 4: pp. 378-82.

[11] Forrest LM, McMillan DC, McArdle CS, Dunlop DJ. An evaluation of the impact of a multidisciplinary team, in a single centre, on treatment and survival in patients with inoperable non-small-cell lung cancer. Br J Cancer 2005; 93(9): 977-8. DOI: $10.1038 /$ sj.bjc.6602825

[12] Abdulrahman GO, Jr. The effect of multidisciplinary team care on cancer management. Pan Afr Med J 2011; 9(1): 20. DOI: 10.4314 pamj.v9i1.71195

[13] MacDermid E, Hooton G, MacDonald M, et al. Improving patient survival with the colorectal cancer multi-disciplinary team. Colorect Dis 2009; 11(3): 291-5. DOI: $10.1111 /$ j.1463-1318.2008.01580.x

[14] Bydder S, Nowak A, Marion K, Phillips M, Atun R. The impact of case discussion at a multidisciplinary team meeting on the treatment and survival of patients with inoperable non-small cell lung cancer. Int Med J 2009; 39(12): 838-41. DOI: $10.1111 /$ j.1445-5994.2009.02019.x

[15] Asghar AH, Abbasi AN, Jamal A, Haider G, Rizvi S. City tumour board Karachi: An innovative step in multidisciplinary consensus meeting and its two years audit. J Pak Med Assoc 2013; 63(12): 1534-5. 
[16] Fader DJ, Wise CG, Normolle DP, Johnson TM. The multidisciplinary melanoma clinic: A cost outcomes analysis of specialty care. J Am Acad Dermatol 1998; 38(5): 742-51. DOI: $10.1016 / \mathrm{S} 0190-9622(98) 70203-8$

[17] Barry MJ, Edgman-Levitan S. Shared decision making-the pinnacle of patient-centered care. New Engl J Med 2012; 366(9): 780-1. DOI: 10.1056/NEJMp1109283

[18] El Saghir NS, Keating NL, Carlson RW. Tumor boards: Optimizing the structure and improving efficiency of multidisciplinary management of patients with cancer worldwide. Am
Soc Clin Oncol Educ Book 2014; e461-6.

DOI: 10.14694/EdBook_AM.2014.34.e461

[19] Schmieder K, Keilholz U, Combs S. The interdisciplinary management of brain metastases. Dtsch Arztebl Int 2016; 113(24): 415. DOI: 10.3238/arztebl.2016.0415

[20] Abbasi AN, Karim MU, Ali N, Hafiz A, Qureshi BM. Multidisciplinary team tumor boards are a lifeline for our cancer patients in lower and middle income countries. Clin Oncol ( R Coll Radiol) 2016; 28(12): 799. DOI: $10.1016 /$ j.clon.2016.07.003 